\title{
O SIGNIFICADO HISTÓRICO DO 'MÉTODO BH' E AS REFLEXÕES DE IAMAMOTO PARA O SERVIÇO SOCIAL BRASILEIRO: INTERPRETAÇÕES DE JOSÉ PAULO NETTO
}

\author{
Rafaela de Sousa Bandeira ${ }^{1}$ \\ Mirtes Nayanne Freitas Costa ${ }^{2}$ \\ Cibelly Michalane Oliveira dos Santos Costa ${ }^{3}$
}

Resumo: O presente trabalho tem como objetivo, trazer as principais análises feitas por lamamoto sobre o significado histórico do Método de Belo Horizonte, tendo como via principal a trajetória sócio-histórica para a profissão de Serviço Social presumidas em três momentos: a perspectiva modernizadora, a reatualização do conservadorismo e a intenção de ruptura. Nessa perspectiva, José Paulo Netto vem nos atentar quais seriam os acertos e equívocos encontrados nas reflexões da autora a cerca do Método Belo Horizonte, como também, analisar as perspectivas e proposituras feitas pelos profissionais representantes da categoria as partir da conjuntura de Ditadura Militar em que a profissão superou e se consolidou.

Palavras-chave: Método Belo Horizonte; Serviço Social; Acertos; Equívocos.

\footnotetext{
${ }^{1}$ Serviço social/Universidade Federal de Campina Grande, Brasil. E-mail: rafaela.sousa.remidos@hotmail.com.

2 Serviço social/Universidade Federal de Campina Grande, Brasil. E-mail: nayanneufcg@hotmail.com.

${ }^{3}$ Serviço social/Universidade Federal de Campina Grande, Brasil. E-mail: cimichalane@hotmail.com.
} 